doi:10.1017/aju.2020.43

\title{
SYMPOSIUM ON AUTHORITARIAN INTERNATIONAL LAW: IS AUTHORITARIAN INTERNATIONAL LAW INEVITABLE?
}

\author{
LEGAL GAMES - POLITICAL GOALS \\ Ian $\mathrm{Hurd}^{*}$
}

"Well, now rules are alright, if there's someone left to play the game"

'Born in Chicago,' The Paul Butterfield Blues Band, 1965

As he searches for differences in how democratic and authoritarian governments use international law, Tom Ginsburg highlights - perhaps inadvertently — the fact that both kinds of regime use law as a tool to advance their goals. Governments' goals may differ, both within and across regime types, but the instrumental use of law in the service of political ends does not. Ginsburg's article permits three distinct readings: it is an effort to show a correlation between regime-type and uses of international law; it is also an argument that the historical-normative core of international law included the promotion of "liberal" goals such as human rights and democracy; and third, it is a defense of the meta-claim that law follows the political purposes of society's powerful actors. This third contribution is the quietest in the article but is arguably the most important. Because the methodological difficulties in correlating regime type with attitude toward international law are insuperable, Ginsburg's contribution is that he directs attention to the substantive goals that governments pursue through law and to the tradeoffs that follow as one goal wins over others. The normative valence of international law depends on how one feels about these practical tradeoffs; those whose interests are harmed by international law have good reason to feel disadvantaged.

The social-scientific effort to prove that democracies behave differently than non-democracies is unconvincing because the data on which it relies is unreliable. But in looking for contrasts, Ginsburg ends up highlighting important ways that they are similar: all governments aim to use international law to advance their interests when they can, and along the way they may be remaking it for the future. If that's true then the crucial feature that needs examining is the political purpose for which law is being used, and Ginsburg opens the way for readers to ask empirical questions about whose political values or interests are advanced and whose are denied: what class, region, interest, values, or actors are helped by international law and at whose expense? Once we drop the pretense that law serves the common good (in whatever way that may be defined) we can start to talk about who the rules are for, who gets to play the game, and who pays the costs.

* Professor, Dept. of Political Science, Northwestern University.

\footnotetext{
(C) Ian Hurd 2020. This is an Open Access article, distributed under the terms of the Creative Commons Attribution licence (http:// creativecommons.org/licenses/by/4.0/), which permits unrestricted re-use, distribution, and reproduction in any medium, provided
} the original work is properly cited. 
Democracy-Data-Deficiency Syndrome

In social science, Ginsburg joins a long line of scholars seeking to measure "the difference that democracy makes." 1 This is often used to explain divergent outcomes on the basis of regime-type. Democracies are said to be different than authoritarian governments in how they make war, make peace, deal with opponents, exercise power, and aggregate interests. Ginsburg adds to the list his finding that they also use international law differently: democracies, he says, tend to invest in the international legal system, follow its rules and institutions, and respect law's commitment to a politics of individual rights and constrained government, while authoritarian governments take advantage of the existing system, instrumentalize it, and use it to reinforce non-democratic forms of political authority.

The extensive research on the correlates of regime type is famous for vague, tenuous, and tendentious claims. ${ }^{2} \mathrm{It}$ is not easy to define democracy and it's even harder to find measurable indicators for it; competing definitions produce competing indicators which are often aggregated into indexes that compound rather than smooth out the difficulties. ${ }^{3}$ The task of sorting countries into two types, democracy and non-democracy, is a little like trying to distinguish jazz music from blues: the more one insists on clear criteria that are mechanically applied across time and place the less sensible the results are likely to be, and the whole exercise is probably most useful when it remains impressionistic and open to ambiguity and inconsistency in the terms.

The problem with regime-type classification schemes is that, by design, they distill complex knowledge to a onedimensional metric. Facts become stylized, and then stylized facts are compared to each other. By losing the nuance, the process risks producing gross concepts that muddle rather than clarify the phenomena. ${ }^{4}$ For instance, scholars coding the quality of democracies must somehow compare the fact that Donald Trump was installed as U.S. president despite coming in second in the popular vote in a two-person electoral race, with the fact that the Cambodian election of 2018 returned Hun Sen to office with a full sweep of 100 percent of the seats in the National Assembly. In both places, mass franchise is permitted but in each it takes place within electoral rules that are designed or manipulated to generate anti-democratic outcomes. Both presidents were "partially elected." To understand the different ways that voting rules produced counter-democratic results requires an investment in nuance, interpretation, and local knowledge to uncover the relationship between rules, practices, manipulation, and various features of the composite-concept of democracy. The social-scientific imperative to generalize a single concept of democracy across time and place is a poor fit for a situation where a complex idea animates diverse, even contradictory, activity as it is invoked by strategic actors.

The "authoritarian international law" project faces a second methodological hurdle when it tries to distinguish among types of usage of international law. These types might be pro-democratic versus anti-democratic, or liberal versus illiberal, or genuine versus insincere, or system-sustaining versus -undermining. Similar to the problem of coding democracies and non-democracies, the effort to catalog the ways governments relate to international law so they can be correlated with regime type assumes a level of clarity in the concepts and in the actions of governments that probably does not exist. Ginsburg provides an excellent example as he notes the controversy over the implied

\footnotetext{
${ }^{1}$ The phrase is a common short-hand in Political Science to describe regime-type comparisons that aim to isolate difference between democratic and authoritarian governments. See, e.g., Meredith L. Weiss, What a Little Democracy Can Do: Comparing Trajectories of Reform in Malaysia and Indonesia, 14 Democratisation 26, 37 (2007).

${ }^{2}$ Key problems with operationalizing “democracy” are laid out in Frederic SCHafFer, Democracy in Translation: Understanding Politics in an Unfamiliar Culture (2000).

${ }^{3}$ Geraldo L. Munck \& Jay Verkuilen, Conceptualizing and Measuring Democracy: Evaluating Alternative Indexes, 35 COMP. POL. STUD. 5 (2002).

${ }^{4}$ Ian Shapiro, Gross Concepts in Political Argument, 17 PoL. THeory 51 (1989).

${ }^{5}$ The term "partially elected" in reference to Donald Trump comes from Andy Zaltzman, The Bugle (April 4, 2020).
} 
right to democratic governance in the 1990s: if such a right exists, it could be seen as an expression of "liberal values" within international law but equally it could be evidence of illiberalism because it diminishes the autonomy of domestic political processes to produce locally legitimated outcomes. The argument among Thomas Franck and his interlocutors deploys competing views on legal theory (i.e., the sources of international law, state practice as a mode of legal change, implied rights and obligations) as well as substantive assumptions about the meaning and implications of self-determination, the reification of "nations" after 1918, the goals of U.S. foreign policy, and the tradeoff between individuals and governments. Various positions on all these issues combine to produce the scholarly debates of the 1990s. This complex terrain does not map neatly onto pro- and anti-liberal categories. Ginsburg defines as illiberal the use of international law to impede "elections; . . . core rights related to political contestation such as ... free speech; and the rule of law, especially as applied to electoral contestation." ${ }^{6}$ This is a sensible definition but it implies an iceberg-worth of interpretive work beneath the surface to operationalize this list of ambiguous terms. When dealing with essentially contested concepts, social-science positivism tends to obscure rather than clarify: we do not know how to define the key idea, and we do not know how to measure the terms, and we disagree about how they relate to real-world events.

The two tasks - measuring democracy and cataloging various uses of international law—are good illustrations of the typical problems that arise when one aims to represent complex social facts as variables. ${ }^{7}$ Social-science positivism sets itself an impossible task as it seeks to isolate one aspect of a phenomenon from the context that gave it meaning. It requires a single, coherent definition of complex and contested ideas and practices and it insists on holding constant concepts that are always changing. Ordinal rankings of the degree of electoral freedom across countries are hard to take seriously, though the political power of such data is significant. It is no surprise that the most popular indexes of democracy are funded by the U.S. government, including the Freedom House ranking that is prominent in the media and the Polity dataset that is widely used by academics. ${ }^{8}$

A skeptical social scientist will not be convinced that Ginsburg has uncovered a robust correlation between regime type and involvement in international law. However, that's not a problem since his contribution does not really rely on data. He is opening a window onto the normative presumptions and political power of international law.

\section{Legal Games for Political Gain}

Ginsburg deploys a pair of assumptions to undergird the research, roughly summarized as instrumentalism and pragmatism. These constitute what might be called his "applied philosophy of international law and social science." The central action in the article comes in how he represents the world of international law in relation to the domain of politics and in the approach he uses to explore the connections between them. He combines an interest in the strategic utility of international law with the recognition that different governments have different policy goals. Together, these chart a path for future scholarship on the politics of international law.

The first directs attention to how international law is used rather than how it is negotiated, what the text says, or who is complying with it. "Uses" imply utility: governments reach for international law when they believe it will improve their position on some desired policy or goal. To be "useful," the tool needs to be relevant to the purpose of the actor and the actor must also see some value in making use of it. The widespread use of international legal discourse is testament to the political value of international law. In Ginsburg's analysis, both democratic and

\footnotetext{
${ }^{6}$ Tom Ginsburg, Authoritarian International Law?, 114 AJIL 221, 225 (2020).

${ }^{7}$ Wendy Nelson Espeland \& Mitchell L. Stevens, A Sociology of Quantification, 49 Eur. J. Soc. 401 (2008); Frederic Schaffer, Elucidating Social Science Concepts: An Interpretive Guide (2015).

${ }^{8}$ The Polity project lost its funding from the US government in early 2020 and is currently seeking new backers.
} 
authoritarian governments use international law instrumentally and this turns out to be more revealing than the effort to systematize the differences between them.

As he unpacks the use of law, Ginsburg encourages scholars to think about what governments are trying to accomplish: that is, their substantive goals, purposes, desires, and ambitions. This is evident in his central claim that "Authoritarians are using international law, building on and repurposing some of the norms of the liberal era, but with very different ends." ${ }^{\prime}$ Even if we are not sure what to make of the categories of democratic and authoritarian, he brings out into the open the fact that to understand how international law works and is used we need to look at the goals governments are pursuing when they make use of it. This is a return to substance in the sense of paying attention to the specific aims of governments and others, and it indicates a research program distinct from the search for "content-independent" reasons that governments make use of international law. ${ }^{10}$

For some scholars, evidence that law is used instrumentally is a sign that the legal system is in trouble - it may indicate "rule by law" rather than "rule of law," in the words of Ginsburg and Moustafa. ${ }^{11}$ This may be a matter of degree, in that at some tipping point too much instrumentalism marks the death of the rule of law, but that is a different debate than the one at stake here. Here, we are talking about whether or not governments (or other actors) use international law instrumentally and the answer is clearly "yes." And if the answer is yes then trying to distinguish "genuine" from "opportunistic" appeals to law becomes less interesting, and we can move away from the idea that there are distinct "logics" of decisions based on appropriateness versus consequences.

Accepting instrumentalism leads legal scholarship to pay more attention to the political content that governments bring to their interaction with international law. ${ }^{12}$ This is a good development. It is obvious that the goals of governments are important for the analysis of international law. Australia's arguments about how to read a treaty in Australia v. Japan are not independent of its desire to impede Japan's whale hunting-these are legal arguments in the service of a political goal. Similarly, U.S. interpretations of the laws of armed conflict in recent years are closely connected with the desire to use drones, cyber attacks, and torture against its enemies. Russia's claims about sovereignty, separatism, and referenda around Crimea are similarly self-serving. But "self-serving" is the baseline to legal argumentation not its negation, and democracies and non-democracies do not appear to differ on this point.

With this in mind, Ginsburg's second contribution is to remind readers that the political payoffs of international law are not universally good. This is both a logical deduction from first principles and an empirical finding: As a matter of logic, it follows that if governments appeal to international law in the pursuit of their goals, then their different uses of law will produce results that are good for them and perhaps not for others; empirically, it motivates his concern that authoritarian governments might remake international law in ways that he sees as undesirable.

Liberal myths of the escape from politics into a harmony of interests through law are a poor foundation for empirical research. ${ }^{13}$ Ginsburg's concern with the political motives of those who use international law directs our attention to research questions that recognize competition among interests: Whose interests are encoded in the law and whose interests are sacrificed? ${ }^{14}$ This is a turn to the empirical over the ideological, and the practical over the abstract, and it can be the start of a broad shift in how we assess the effects of international institutions and rules.

\footnotetext{
${ }^{9}$ Ginsburg, supra note 6, at 225.

${ }^{10}$ Samantha Besson, Law Beyond the State: A Reply to Liam Murphy, 28 EJIL 233, 237 (2017).

11 Rule by Law: The Politics of Courts in Authoritarian Regimes (Tom Ginsburg \& Tamir Moustafa eds., 2008).

12 Monica Hakimi, The Work of International Law, 58 Harv. INT'L L.J. 1 (2017).

13 Judith N. Shklar, Legalism: Law, Morals, and Political Trials (1986).

${ }^{14}$ Ian Hurd, The Case Against International Cooperation, INT'L THEORY (forthcoming, 2020).
} 
His second turn highlights the reconstitutive effects of the use of international law. Rules, norms, and laws are changed through the practices of agents using them, and the agents are also changed by their interaction with changing international law. The interaction between meaning and practice is crucial for the political content of international law. It reconciles the stability of formal legal texts and institutions with the changing desires of those who both use and are governed by them. Practice is the via media between politics and law, adding dynamism to both and anchoring them to each other and to the contemporary social and political context.

The attention to purposes and to reconstitution-through-use complicates the progressive normative story that is often told about international law. It also undermines the social-science aspiration for general models of causeand-effect. If one accepts that the same legal institution can have different effects depending on the political desires of the governments that employ it, then it is hard to make any generalization about the kinds of outputs to expect from legalization. And further, it is implausible to believe that these outputs will always be worth defending on moral or political grounds.

\section{Conclusion}

In the end, we find ourselves back at the distinction between democratic and authoritarian uses of international law. For all the effort invested in finding and explaining the differences in how different kinds of governments relate to international law, Ginsburg is most persuasive when he illuminates what they have in common. They all look to international law as a resource that can be usefully deployed in advancing their goals. Their goals vary-regime survival, aiding some corner of the economy, turning the policy of a foreign government in a favorable direction, crushing opponents-but the political use of legal resources is the same. This perhaps should not be a surprise since the comparative project in political science often forgets the role of similarities in understanding differences. "Comparison must be a two-edged sword" says Charles Meier; "it establishes what is common in contrast to what is distinctive." 15 In looking for contrasts in how different governments use international law, Ginsburg finds something in common: the instrumentalization of international legalization in the service of political objectives. And so, while the social-science component of his article gets top billing, it is the legal and political theory behind it that should spark the most conversation.

${ }^{15}$ Charles S. Maier, The Unmasterable Past: History, Holocaust, and German National Identity 84 (1988). 